\title{
Reduced sodium intake lowered blood pressure and need for antihypertensive medication
}

\author{
Appel LJ, Espeland MA, Easter L, et al. Effects of reduced sodium intake on hypertension control in older individuals. \\ Results from the Trial of Nonpharmacologic Interventions in the Elderly (TONE). Arch Intern Med 2001 Mar \\ 12;161:685-93. \\ QUESTION: In older adults with hypertension, is a reduced dietary sodium (RS) \\ intervention more effective than usual lifestyle (UL) in controlling blood pressure and \\ preventing cardiovascular events?
}

\section{Design}

Randomised \{allocation concealed*\}t, blinded (outcome assessors),* controlled trial with 30 months follow up.

\section{Setting}

4 clinical centres in the US.

\section{Patients}

681 patients who were $60-80$ years of age (mean age 66 y, 53\% men) and had systolic blood pressure (SBP) $<145 \mathrm{~mm} \mathrm{Hg}$ and diastolic blood pressure (DBP) $<85 \mathrm{~mm} \mathrm{Hg}$ while taking 1 antihypertensive medication (AM). Exclusion criteria were use of AM for conditions other than hypertension, myocardial infarction (MI) or stroke in the previous 6 months, angina pectoris, congestive heart failure (CHF), serum creatinine concentration $>176.8 \mu \mathrm{mol} / \mathrm{l}$, blood glucose concentration $>14.4 \mathrm{mmol} / \mathrm{l}$, or average alcohol intake $>14$ drinks per week. Follow up was $90 \%$ to $93 \%$.

\section{Intervention}

Patients were allocated to RS $\{\mathrm{n}=340\} \ddagger$ or UL $\{\mathrm{n}=341\} \ddagger$. RS group patients attended weekly to biweekly individual and group sessions with a registered dietitian to achieve and sustain an RS lifestyle and a 24 hour dietary sodium intake of $\leqslant 80 \mathrm{mmol} / \mathrm{l}$. UL group patients attended regular meetings with discussions on topics unrelated to BP, cardiovascular disease, or nutrition. Patients in both groups began withdrawal of AM 90 days after the first RS intervention session.

\section{Main outcome measures}

The primary end point was the need for or resumption of AM. The end point was reached when any of the following occurred: increased BP (SBP $\geqslant 190 \mathrm{~mm} \mathrm{Hg}$ and $\mathrm{DBP} \geqslant 110 \mathrm{~mm} \mathrm{Hg}$ at 1 visit); AM required for a condition other than increased BP or cardiovascular event; or a cardiovascular event (MI, angina, CHF, or stroke) or procedure.

\section{Main results}

Patients in the RS group had greater reductions in BP from baseline than patients in the UL group $(p \leqslant 0.001)$ (table). Between group differences were seen for SBP for all subgroups defined by sex, ethnicity, age, and weight except the 70 to 80 year old group. More patients in the RS group remained end point free than patients in the UL group $(\mathrm{p}<0.001)$ (table). The groups did not differ for cardiovascular events.

\section{Conclusion}

In older adults with hypertension, an intervention aimed at reducing sodium intake lowered blood pressure and the need for antihypertensive medication.

*See glossary.

†Information provided by the author.

¥Whelton PK, Appel LJ, Espeland MA, et al. JAMA 1998;279:839-46.

Source of funding: National Institutes of Health.

For correspondence: Dr LJ Appel, Johns Hopkins University, 2024 East Monumen Street, Suite 2-645, Baltimore, $M D$ 21205-2223, USA

Reduced sodium (RS) v usual lifestyle (UL) at 30 months

\begin{tabular}{lllll} 
Outcomes & RS & UL & $\begin{array}{l}\text { Difference in mean decrease } \\
(95 \% \mathrm{Cl})\end{array}$ \\
$\begin{array}{c}\text { Change from baseline in SBP } \\
\text { (mm Hg) }\end{array}$ & -4.6 & -0.4 & $4.3(2.5$ to 6.0$)$ & \\
\hline $\begin{array}{c}\text { Change from baseline in DBP } \\
\text { (mm Hg) }\end{array}$ & -2.2 & -0.2 & $2.0(0.8$ to 3.2$)$ & \\
\hline & & & $\begin{array}{l}\text { Relative hazard ratio } \\
(\mathrm{CI})\end{array}$ & NNT (CI) \\
\hline End point free & $36 \%$ & $21 \%$ & $0.68(0.56$ to 0.82$)$ & 8 (5 to 17$)$ \\
\hline
\end{tabular}

$\S \mathrm{DBP}=$ diastolic blood pressure, $\mathrm{SBP}=$ systolic blood pressure. Other abbreviations defined in glossary; NNT and $\mathrm{Cl}$ calculated from data in article.

\section{COMMENTARY}

In the study by Appel $e t a l$, an average net reduction in sodium intake of $40 \mathrm{mmol} /$ 24 hours lowered BP by $4.3 / 2 \mathrm{~mm} \mathrm{Hg}$. This magnitude of change in BP is similar to that found in a review of the effect of age on the response to sodium. ${ }^{1}$ Clinicians may not be impressed with such reductions in BP, but they may translate into substantial reductions in cardiovascular disease. ${ }^{2}$ Still, there is no clinical trial evidence that low-sodium diets decrease morbidity and mortality. However, 2 cohort studies showed a substantive direct relation between sodium intake and cardiovascular disease, at least in overweight people. $^{34}$

Prescribing a restriction in sodium intake can be unpopular with patients because most processed foods have high sodium content and the average sodium intake in western countries is about $150 \mathrm{mmol} / \mathrm{d}$. The addition of table salt to cooking accounts for only $20 \%$ of daily intake and thus simply eliminating table salt is not sufficient to achieve the sodium-restricted diet described in this study. Patients will need to prepare almost all their food including low-salt bread in order to restrict their sodium intake to the required level. Still, the human palate rapidly acclimates to different levels of sodium intake.

I would have to agree with others who suggest that patients try weight loss, reduced alcohol intake, and regular moderate exercise before prescribing sodium restriction (unless the patient is motivated enough to try) as non-pharmacological therapy for hypertension. ${ }^{5}$

Bruce Arroll, $\mathrm{MBChB}, \mathrm{PhD}$ University of Auckland Auckland, New Zealand

1 Law MR, Frost CD, Wald NJ. BMJ 1991;302:811-5.

2 Collins R, Peto R, MacMahon S, et al. Lancet 1990;335:827-38.

3 He J, Ogden LG, Vupputuri S, et al.JAMA 1999;282:2027-34.

4 Tuomilehto J, Jousilahti P, Rastenyte D, et al. Lancet 2001;357:848-51.

Nicholls MG, Richards AM. Med J Aust 1999;170:178-80. 